\title{
Thermogravimetric Study of the Decomposition of BSA-Coated Magnetic Nanoparticles
}

\author{
K. Csach, A. Juríková, J. Miškuf, M. Koneracká, V. ZÁvišová, M. KubovČíková \\ AND P. KOPČANSKÝ
}

Institute of Experimental Physics, Slovak Academy of Sciences, Watsonova 47, 04001 Košice, Slovakia

\begin{abstract}
Magnetic nanoparticles used in biomedicine have to be biocompatible, which can be achieved by the modification of the magnetic particle surface with an appropriate biocompatible substance. In the work protein bovine serum albumin (BSA) was chosen to modify the surface of magnetic nanoparticles. The BSA-coated magnetic nanoparticles with different input weight ratios of BSA to the magnetite $\mathrm{Fe}_{3} \mathrm{O}_{4}$ were prepared and thermally characterized using thermogravimetric and differential scanning calorimetric analysis. The adsorption of BSA on the magnetic nanoparticles in wide range of concentration was confirmed. The activation energies of the thermal decomposition of the complex system were estimated.
\end{abstract}

PACS: 47.65.Cb, 65.80.- g

\section{Introduction}

Current problems of enhancement of selective drug actuation in certain tissue can be solved using unique properties of magnetic nanoparticles. Due to the possibility to influence the motion of iron-oxide nanoparticles by the external magnetic field, the magnetic fluids are a serious candidate for drug carrier. For the stability of the magnetic fluid, coating of magnetic nanoparticles with a surfactant is necessary. For this purpose the most used is sodium oleate. The use of magnetic fluids in medical applications needs the additional covering of magnetic nanoparticles by biocompactible macromolecules $[1,2]$. Thermoanalytical methods can play the important role in the study of the bonding of biochemical substances on the magnetic nanoparticles.

\section{Experimental}

The magnetic $\mathrm{Fe}_{3} \mathrm{O}_{4}$ particles were synthesized by a chemical co-precipitation procedure [3]. Ferrous sulphate heptahydrate $\left(\mathrm{FeSO}_{4} \cdot 7 \mathrm{H}_{2} \mathrm{O}\right)$ and ferric chloride hexahydrate $\left(\mathrm{FeCl}_{3} \cdot 6 \mathrm{H}_{2} \mathrm{O}\right)$ with molar ratio of $1: 2$ were dissolved in deionised water and alkali medium was added to obtain black magnetite precipitate. The stabilization of the magnetite precipitate was achieved by adding sodium oleate $\left(\mathrm{C}_{17} \mathrm{H}_{33} \mathrm{COONa}\right.$, theoretical ratio $1.1 \mathrm{~g}$ to $1.5 \mathrm{~g}$ of $\mathrm{Fe}_{3} \mathrm{O}_{4}$ ) during stirring and heating until the boiling point was reached. Then centrifugation at $9000 \mathrm{rpm}$ during 30 min followed. The system at this stage is investigated below as initial magnetic fluid and referred to as MF. Finally, bovine serum albumin BSA (molecular weight of $66 \mathrm{kDa}$ ) was added into the initial fluid MF. BSA was chosen for the modification of magnetic nanoparticles due to the high sequential homology of BSA (76\%) with human serum albumin. The feed amounts of BSA were added into the system in the range of $0.25-25 \mathrm{~g}$ of BSA per $1 \mathrm{~g}$ of $\mathrm{Fe}_{3} \mathrm{O}_{4}$. The mixture was heated up to $\mathrm{ca} .50^{\circ} \mathrm{C}$ and stirred for half an hour and then left to cool down to the room temperature. In this way, the magnetic fluid MFBSA was formed.

Thermogravimetry (TG) was carried out using SETARAM Setsys TGDTA analyzer in 5N purity Ar with flow of $100 \mathrm{ml} / \mathrm{min}$ under heating with the rate of $10^{\circ} \mathrm{C} / \mathrm{min}$ up to $750^{\circ} \mathrm{C}$. The decomposition rate dependences (DTG) were obtained by numerical differentiation of TG dependences. Differential scanning calorimetry (DSC) was performed using Perkin Elmer DSC 8000 calorimeter in flowing nitrogen atmosphere at heating rate of $5^{\circ} \mathrm{C} / \min$ up to the temperatures of $110^{\circ} \mathrm{C}$.

\section{Results and discussion}

DSC traces of dried MFBSA complex in the wide range of concentrations of BSA are shown in Fig. 1. For comparison, DSC traces for pure BSA and the initial MF are added. It is shown that in the temperature interval up to $110^{\circ} \mathrm{C}$, a wide peak is present. This endothermic effect is connected with the denaturation of BSA [4]. As BSA concentration increases, this peak becomes higher and it is shifted to the higher temperatures.

Normalized temperature dependences of the weight loss for dried MF, pure BSA, pure sodium oleate and MFBSA with BSA/magnetite ratio of 0.5 are shown in Fig. 2. At temperatures up to $100{ }^{\circ} \mathrm{C}$ the weight decrease is associated with $\mathrm{BSA}$ denaturation in the accordance to DSC measurements mentioned above. At temperatures over $400{ }^{\circ} \mathrm{C}$ pure sodium oleate starts to evaporate. 


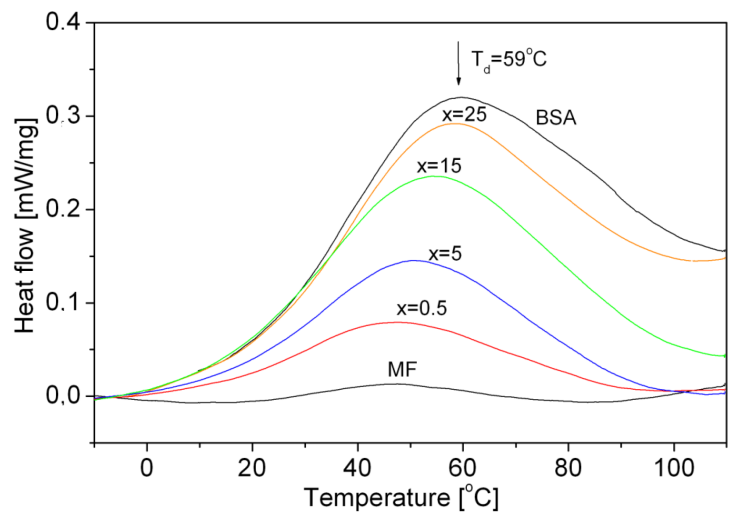

Fig. 1. DSC traces of dried magnetic fluid MFBSA for chosen $\mathrm{BSA} / \mathrm{Fe}_{3} \mathrm{O}_{4}$ ratios $x$.

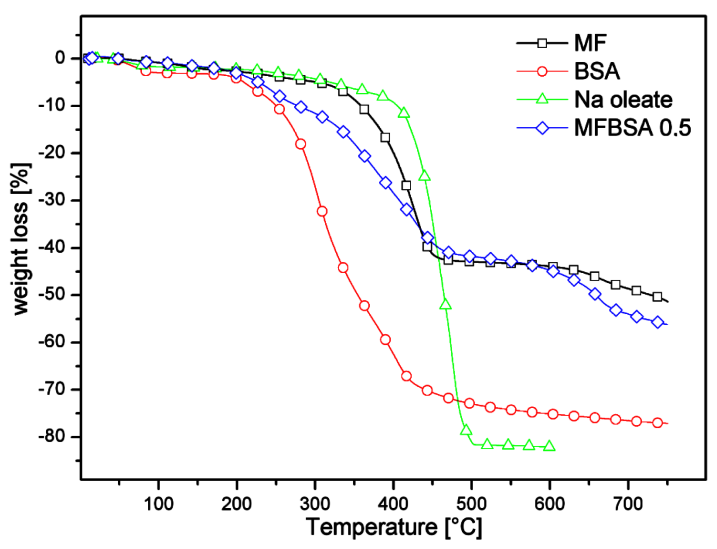

Fig. 2. Thermogravimetric traces for the dried magnetic fluid MFBSA with BSA/magnetite ratio of 0.5 and for its pure components (i.e. sodium oleate, MF and BSA).

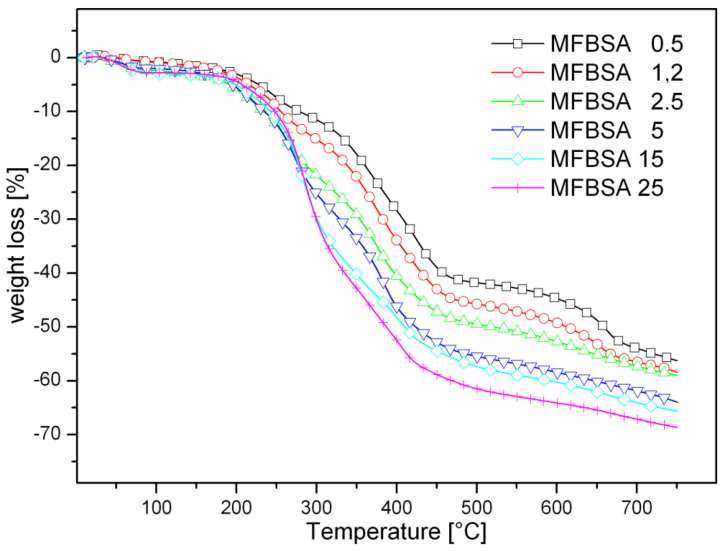

Fig. 3. Thermogravimetric traces of dried MFBSA complex for denoted $\mathrm{BSA} / \mathrm{Fe}_{3} \mathrm{O}_{4}$ ratios.

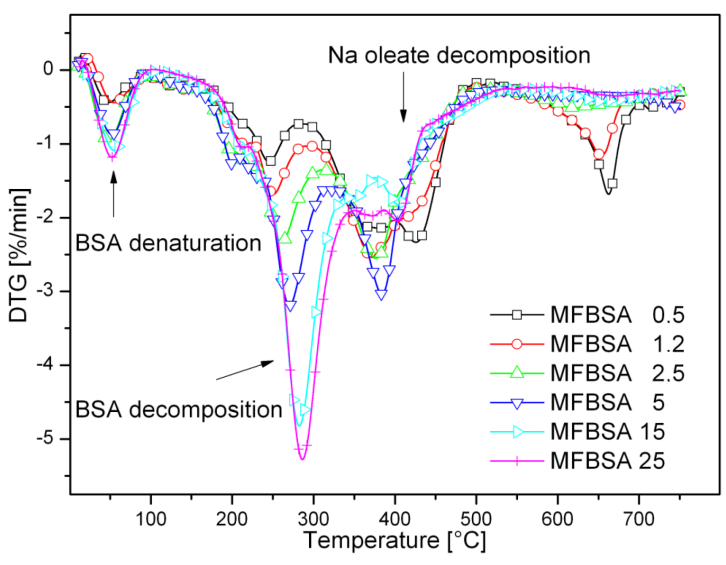

Fig. 4. Temperature dependences of the weight loss rate of dried magnetic fluid MFBSA for different BSA/ $\mathrm{Fe}_{3} \mathrm{O}_{4}$ ratios.

If the sodium oleate covers the magnetite nanoparticles (MF and MFBSA 0.5), the evaporation temperature becomes lower, so the magnetite acts as a pyrolysis stimulator. Pure BSA starts to decompose at temperatures over $220^{\circ} \mathrm{C}$. Pyrolysis of complex MFBSA magnetic fluid occurs in the temperature interval between pure BSA and pure MF decomposition temperatures.

Measured decomposition curves of samples in the whole concentration interval are shown in Fig. 3 and the curves after their numerical derivations can be seen in Fig. 4. The stepwise weight loss is discussed using derivative curves. First peak is related to the denaturation of BSA. In the temperature interval of $180-500^{\circ} \mathrm{C}$ four peaks are overlapped. In this temperature interval, BSA and sodium oleate decompositions occur. We suggest that clearly visible shift of the maximum of the decomposition rate with BSA concentration is the confirmation that BSA is adsorbed on the magnetic nanoparticles. The increase of rate of BSA pyrolysis in MFBSA does not depend on the concentration of BSA. The interpretation of other peaks needs further investigations.

For better distinguishing the pyrolysis of BSA and sodium oleate we studied the kinetics of the decomposition of the sample with $\mathrm{BSA} / \mathrm{Fe}_{3} \mathrm{O}_{4}$ ratio of 0.5 . Figure 5 shows the thermogravimetric curves measured at heating rates (HR) in the interval from 1.25 to $20^{\circ} \mathrm{C} / \mathrm{min}$. Kissinger's plots [5] for all six DTG peaks (enumerated from the left side) were made. The results are shown in Fig. 6.

Table summarizes the calculated apparent activation energies for all observed peaks. There can be seen the tendency to increase the slope $E / R$ ( $E$ is the apparent activation energy and $R$ is universal gas constant) of Kissinger's plot with increasing peak temperatures. It can be supposed that for higher BSA/magnetite ratio, the access of BSA (i.e. the presence of BSA non-adsorbed on magnetite nanoparticles) is expected. So, further study for description of MFBSA decomposition process is necessary. 


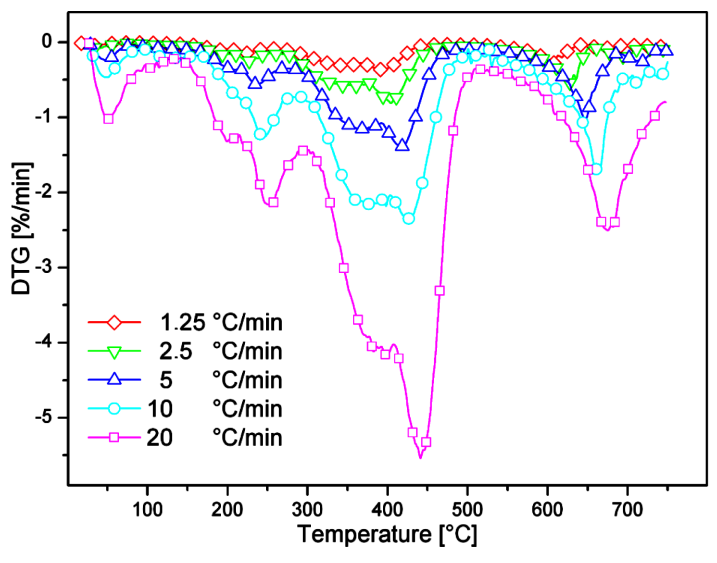

Fig. 5. Temperature dependences of weight loss rate of dried MFBSA complex for $\mathrm{BSA} / \mathrm{Fe}_{3} \mathrm{O}_{4}$ ratio $x=0.5$ measured at different heating rates $(\mathrm{HR})$.

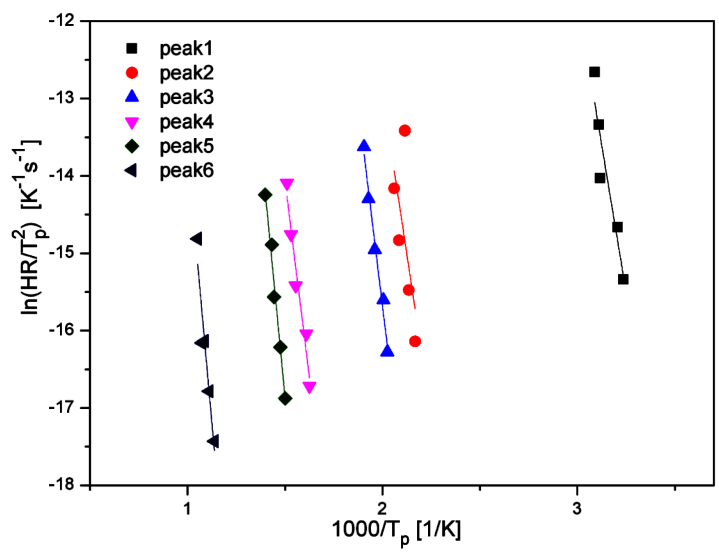

Fig. 6. Kissinger's plot for DTG peaks from Fig. 5 ( $T_{\mathrm{p}}$ is the peak maximum temperature).

\section{Conclusion}

The BSA-coated magnetic nanoparticles with different input weight ratios of BSA to the magnetite were prepared and thermally characterized using thermogravimetric and differential scanning calorimetric analysis.

\section{TABLE}

Kissinger's plot slope $(E / R, E$ - activation energy, $R$ - gas constant) with its standard errors for peaks from Fig. 6 .

\begin{tabular}{l|c|c}
\hline \hline & $E / R$ & Std. error \\
\hline peak1 & 15.18 & 312 \\
peak2 & 16.76 & 11.19 \\
peak3 & 20.76 & 1.48 \\
peak4 & 20.32 & 2.38 \\
peak5 & 26.01 & 1.95 \\
peak6 & 28.15 & 4.69
\end{tabular}

The increase of BSA/magnetite ratio leads to the shift of the broad BSA denaturation peak to higher temperatures. The adsorption of the biocompatible material BSA on magnetic nanoparticles in the wide range of concentrations was confirmed. The activation energies of thermal decomposition steps of the studied complex system were estimated using Kissinger's plots.

\section{Acknowledgments}

This work was supported by implementation of the projects Nos. 26220120021 and 26220120033 provided by the European Regional Development Fund. The authors are also grateful to the Slovak Academy of Sciences the Centre of Excellence "Nanofluid", VEGA No. 0185/11 and Slovak Research and Development Agency - contract No. APVV-0171-10.

\section{References}

[1] Ch.A. Haynes, W. Norde, J. Colloid Interface Sci. 169, 313 (1995).

[2] A. Juríková, K. Csach, J. Miškuf, M. Koneracká, V. Závišová, P. Kopčanský, Acta Phys. Pol. A 118, 990 (2010).

[3] H. Fessi, F. Puisieux, J.P. Devissaguet, N. Ammoury, S. Benita, Int. J. Pharm. 55, R1 (1989).

[4] A. Michnik, J. Therm. Anal. Cal. 71, 509 (2003).

[5] H.E. Kissinger, Anal. Chem. 29, 1702 (1957). 